\title{
EVALUACIÓN NUTRICIONAL DE LOS ÁCIDOS GRASOS DE ACEITE DE SEMILLAS DE PALQUI (Acacia feddeana Harms)
}

\section{Ramiro Escalera y Francisco Caba}

\section{RESUMEN}

Se presenta una evaluación nutricional de los aceites extraídos de la semilla de palqui (Acacia feddeana Harms), una planta leguminosa de origen silvestre, que crece en zonas semi-desérticas templadas de la región sud de Bolivia y es consumida tradicionalmente por los campesinos productores, como semilla cocida o tostada.

El aceite extraído de las semillas de palqui contiene, mayoritariamente, ácido oleico, 43,4\%, un ácido graso monoinsaturado (AGMI) y ácido linoleico (AL), 35,8\%. Tambien contiene pequeñas cantidades $(1,46 \%)$ de ácido $\alpha$ linolénico (AAL). El ácido linoleico y el $\alpha$ - linolénico, ácidos grasos poliinsaturados (AGPI), son esenciales en la alimentación, como precursores de las familias de ácidos grasos de cadenas más largas, $\omega-6$ y $\omega-3$, respectivamente. Entre los ácidos grasos saturados (AGS), que constituyen el 18,3\% restante, el ácido palmítico (10,3\%) y el ácido esteárico $(7,3 \%)$ son los mayoritarios.

Los aportes energéticos, \%E, de las proteínas, carbohidratos y la materia grasa, son: $37,4 \% \mathrm{E}, 34,8 \% \mathrm{E}$ y $27,7 \mathrm{E} \%$, respectivamente. El aporte calórico de la materia grasa, está por debajo de las recomendaciones de la FAO/OMS, siendo 5,08\% E el de los AGS $(<10 \% \mathrm{E}), 12,03 \% \mathrm{E}$ el de los AGMI y 10,3\% E el de los poliinsaturados, AGPI (< $11 \% \mathrm{E})$. Sin embargo, el aporte energético del AL, es mayor al máximo recomendado $(9,9>9 \% \mathrm{E})$ y el del AAL, es menor al mínimo recomendado $(0,4<0,5 \% \mathrm{E})$. Estos datos indican que existe un desbalance entre estos dos ácidos esenciales, haciendo necesaria la combinación en la dieta, con aceites ricos en AAL y otros $\omega-3$ AGPI, como el de pescado.

Tomando en cuenta los resultados de esta evaluación, se puede concluir que el consumo de semillas de palqui y su aceite, son beneficiosos y no riesgosos para la salud. Por consiguiente, la semilla de palqui puede ser industrializada como aceite comestible.

Palabras Clave: Aceite de Semillas de Palqui, Ácidos Grasos, Evaluación Nutricional. 